\title{
Transvaginal Sonographic Evaluation of the Cervix in Asymptomatic Singleton Pregnancy and Management Options in Short Cervix
}

\author{
Resul Arisoy ${ }^{1}$ and Murat Yayla ${ }^{2}$ \\ ${ }^{1}$ Department of Obstetrics and Gynaecology, Gole State Hospital, 34660 Ardahan, Turkey \\ ${ }^{2}$ Department of Perinatology, Obstetrics and Gynecology, International Hospital, 34660 Istanbul, Turkey
}

Correspondence should be addressed to Resul Arisoy, drresular@hotmail.com

Received 27 March 2011; Accepted 2 November 2011

Academic Editor: Yves Jacquemyn

Copyright (C) 2012 R. Arisoy and M. Yayla. This is an open access article distributed under the Creative Commons Attribution License, which permits unrestricted use, distribution, and reproduction in any medium, provided the original work is properly cited.

\begin{abstract}
Preterm delivery (PTD), defined as birth before 37 completed weeks of gestation, is the leading cause of perinatal morbidity and mortality. Evaluation of the cervical morphology and biometry with transvaginal ultrasonography at 16-24 weeks of gestation is a useful tool to predict the risk of preterm birth in low- and high-risk singleton pregnancies. For instance, a sonographic cervical length (CL) $>30 \mathrm{~mm}$ and present cervical gland area have a $96-97 \%$ negative predictive value for preterm delivery at $<37$ weeks. Available evidence supports the use of progesterone to women with cervical length $\leq 25 \mathrm{~mm}$, irrespective of other risk factors. In women with prior spontaneous PTD with asymptomatic cervical shortening ( $\mathrm{CL} \leq 25 \mathrm{~mm}$ ), prophylactic cerclage procedure must be performed and weekly to every two weeks follow-up is essential. This article reviews the evidence in support of the clinical introduction of transvaginal sonography for both the prediction and management of spontaneous preterm labour.
\end{abstract}

\section{Introduction}

Preterm delivery occurs in $5-13 \%$ of pregnancies before 37 weeks' gestation. Preterm delivery is a major cause of perinatal morbidity and mortality [1-7]. Most of the damage and death cases occur in infants delivered before 34 weeks. The incidence of early preterm delivery ( $<34$ gestational weeks') is $1-3.6 \%[1,2]$. Preterm delivery is associated with a high prevalence of severe neurological deficits and developmental disabilities and is a leading cause of infant and neonatal mortality. Preterm neonates are at increased risk of developing respiratory distress syndrome, bronchopulmonary dysplasia, sepsis, intraventricular hemorrhage, patent ductus arteriosus, necrotizing enterocolitis, and disorders related to gestational age at birth $[8,9]$.

Risk factors for preterm delivery include demographic characteristics, behavioral factors, and aspects of obstetric history such as previous preterm birth. Demographic factors for preterm labor include black race, extremes of maternal age $(<18$ or $>35)$, low socioeconomic status, and low prepregnancy weight. Preterm labor and birth can be associated with stressful life situations (e.g., domestic violence, close family death, work and home environment) either indirectly by associated risk behaviors or directly by mechanisms not completely understood. Many risk factors may manifest in the same gravida $[1-3,10]$.

The exact mechanism of preterm labor is largely unknown but is believed to include decidual hemorrhage (e.g., abruption, mechanical factors such as uterine overdistension from multiple gestation or polyhydramnios), cervical incompetence (e.g., cone biopsy), müllerian duct abnormalities, fibroid uterus, cervical inflammation (e.g., resulting from bacterial vaginosis, trichomonas), maternal inflammation and fever (e.g., urinary tract infection), hormonal changes (e.g., mediated by maternal or fetal stress), and uteroplacental insufficiency (e.g., hypertension, insulin-dependent diabetes, drug abuse, smoking, alcohol consumption). Each of these underlying causes can initiate the cascade of events that ultimately lead to uterine activity and cervical dilation. Thus, a reduction in the spontaneous PTD rate may require 
not only accurate identification of patients at risk for preterm delivery but also effective treatment strategies aimed at correcting the underlying causes of preterm labor $[1-3,10-16]$.

Methods used for predicting preterm birth include risk scoring system, assessments of salivary estriol, fetal fibronectin (FFN), maternal serum alpha fetoprotein (MS-AFP), cervicovaginal intracellular adhesion molecule-1 (ICAM1), phosphorylated insulin-like growth factor binding protein-1 (phIGFBP-1), cervicovaginal beta-human chorionic gonadotropin ( $\beta$-hCG), and the cervical morphology and biometry. While hospital tocodynamometry has been effective for monitoring uterine contractions to evaluate preterm labor, home uterine activity monitoring (HUAM) has not been proven valuable in detecting or preventing preterm birth and is not currently recommended for use $[17,18]$.

\section{Biomarkers of Preterm Birth}

The most commonly used and most predictive method for preterm birth is fetal fibronectin. Fetal fibronectin (fFN) is a glycoprotein produced by fetal membranes and trophoblasts which form a biological glue that adheres the fetal membranes and placenta to the decidua. Before approximately 20 gestational weeks it is normally found (4\%) in secretions of the cervix and vagina. Thereafter it is a pathological finding and a marker of choriodecidual disruption [19-21]. Initially, Lockwood et al. reported that the presence of cervicovaginal fetal fibronectin in the second and third trimesters of pregnancy identifies a subgroup of women who are at high risk for preterm delivery. They showed that fFN had a sensitivity of $81.7 \%$ and specificity of $82.5 \%$ for detecting PTD at 37 weeks of gestation in asymptomatic patients [19]. The systematic review by Honest et al. demonstrated that in asymptomatic women the best summary likelihood ratio for positive fFN results was 4.01 (95\% confidence interval 2.93 to 5.49) for predicting birth before 34 weeks' gestation, with corresponding summary likelihood ratio for negative fFN results of 0.78 ( 0.72 to 0.84$)$. Among symptomatic women the best summary likelihood ratio for positive results for fFN was 5.42 (4.36 to 6.74) for predicting birth within 7-10 days of testing, with corresponding ratio for negative fFN results of 0.25 (0.20 to 0.31$)$ [22].

Recently, cervical or vaginal fetal fibronectin is the most powerful biochemical prediction marker of SPTD due to the high negative predictive values $[23,24]$. Deplange et al. investigated a sequential test with fetal fibronectin detection after ultrasound measurement of cervical length to predict preterm delivery in women with preterm labor. They reported that the sensitivity, specificity, and positive and negative predictive values of fetal fibronectin positiveness were $75,71,17$, and $97 \%$ for delivery within 14 days; those of cervical length inferior or equal to $20 \mathrm{~mm}$ were $75,52,21$, and $92 \%$ for delivery before 34 weeks. The efficiency of the sequential test was similar with excellent negative predictive value: sensitivity, specificity, and positive and negative predictive values of $75,63,26$, and $93.5 \%$ for prediction of preterm delivery before 34 entire weeks. The use of this sequential test could have avoided $37 \%$ of fibronectin tests [25].
The maternal salivary E3 level seems to correlate well with the serum level and it has been shown that elevated maternal serum E3 levels are associated with increased risk of preterm birth in asymptomatic and symptomatic women presenting for symptoms of preterm labor [26]. It also has low sensitivity and is currently mainly used in clinical settings due to its negative predictive value (i.e., women who test negative are at very low risk of preterm birth and no interventions are necessary) $[17,27]$. This test is thus currently more useful for research than for clinical practice [27].

Previous research has showed an association with elevated AFP and adverse pregnancy outcomes, including spontaneous preterm birth. The premature delivery screening can be used at the beginning of the 2 nd trimester. Cut-off value of 1.8 MoM for marking the higher-risk group was used for marking the high-risk group. Women with equal or higher values of AFP were 3.8 times more likely to have premature delivery than those with lower AFP values (95\% CI: $2.2 ; 6.3$ ). Sensitivity of $25 \%$ and specificity of $92 \%$ were proven [28]. At a patient-level meta-analysis of 24 studies by Yuan et al., there was no association with preterm birth $(\mathrm{OR}=1.80$, 95\% CI: 0.92-2.68) at women in whom AFP was elevated in isolation. Their findings suggest that maternal AFP levels are strongly related to preterm birth, but only in the context of other abnormal pregnancy markers [29].

Marvin et al. reported that measurement of sICAM-1 in cervicovaginal fluid has potential as a predictor of preterm delivery in women with symptoms of preterm labor. Elevated sICAM-1 concentrations predicted short intervals to delivery (area under receiver operator characteristic (ROC) curves, 0.70-0.72 for delivery within 3, 7, and 10 days), with high specificity. Characteristics for delivery within 3 days at a $3 \mathrm{ng} / \mathrm{mL}$ threshold for a positive test were sensitivity of $33.3 \%$, specificity of $98.9 \%$, and positive and negative predictive values of $75.0 \%$ and $93.9 \%$, respectively. Predictive ability was independent of and complementary to that of fetal fibronectin [30]. Kwon et al. showed that ICAM-1 gene K469E polymorphism may be a candidate region and useful predictor of susceptibility to PTD [31].

The recent studies showed that a new cervicovaginal test to detect phosphorylated insulin-like growth factor binding protein-1 (phIGFBP-1) may improve the accuracy of predicting preterm delivery. The phIGFBP-1 is mainly secreted by maternal decidual cells and may be an indicator of tissue damage of the choriodecidual interface. In the first trimester, $24.5 \%$ of women, and in the mid-second trimester, $20.2 \%$ of women, had an elevated cervical fluid phIGFBP-1 level $[32,33]$. Rahkonen et al. investigated an assessment of phIGFBP-1 in predicting preterm delivery in 5180 unselected pregnant women. They found that the rates of spontaneous PTD before 32 and before 37 weeks of gestation were higher in women with an elevated cervical fluid phIGFBP-1 level, compared with women who had cervical phIGFBP-1 of $<10$ micrograms/L (1.1\% versus $0.3 \%$ and $5.7 \%$ versus $3.2 \%$, resp.). An elevated phIGFBP-1 level in the first trimester was an independent predictor for PTD before 32 and before 37 weeks of gestation, with odds ratios of 3.0 (95\% CI 1.3-7.0) and 1.6 (95\% CI 1.2-2.3), respectively. Cervical phIGFBP-1 levels of 10 micrograms/L or more in the first 
trimester predicted PTD before 32 and before 37 weeks of gestation, with sensitivities of $53.8 \%$ and $37.0 \%$, respectively. The negative predictive values were $99.7 \%$ and $96.8 \%$. They showed that elevated cervical fluid phIGFBP-1 levels in the first trimester were associated with an increased risk of spontaneous PTD [34].

In another study, Rahkonen et al. investigated that short cervix $(<25 \mathrm{~mm})$, positive phIGFBP-1 test, combination of both, and clinician's judgment were all associated with preterm delivery $<$ or $=34$ weeks or within 14 days in a total of 246 women between 22 and 34 weeks of gestation. The negative predictive values for delivery $<$ or $=34$ weeks were 97.4, 97.6, 97.1, and 98.7\%, respectively, and within 14 days 98.7, 99.0, 98.3 and 99.6\%, respectively. The corresponding positive LRs for delivery $<$ or $=34$ weeks were $6.8,3.8,75.0$, and 14.9 , and within 14 days 9.7, 5.5, 107.3, and 17.1. The negative LRs were $0.6,0.6,0.7$, and 0.3 and $0.5,0.3,0.6$, and 0.2 . They showed that the rapid phIGFBP-1-test has a high negative predictive value for preterm delivery, comparable to that of ultrasonographic cervical length measurement [35]. Paternoster et al. assessed phIGFBP-1 in cervical secretions and the sonographic measurement of cervical length in 210 symptomatic patients. They found that $26 \mathrm{~mm}$ was the best cut-off value for cervical length in terms of predicting preterm delivery (LR+, 3.69; LR-, 0.22), with a sensitivity of $86.4 \%$, specificity of $71.9 \%$, positive predictive value (PPV) of $34.5 \%$, and negative predicting value (NPV) of $96.8 \%$. They also found that the sensitivity, specificity, PPV, and NPV of phIGFBP-1 of a positive phIGFBP-1 test were $52.9 \%$, $89.2 \%, 48.7 \%$, and $90.8 \%$, respectively, in predicting birth before 37 weeks' gestation with an OR of 9.3 (95\% CI, 4.0521.3), an LR+ of 4.9, and an LR- of 0.5 and that their combination had an NPV of $90 \%$, greater specificity, and a better PPV (64.3\%) than either method alone for preterm delivery [36]. Bittar et al. found that measuring cervical length at 22-24 weeks' gestation and phIGFBP-1 at 30 weeks' gestation improved the prediction of preterm delivery over either method used alone [37].

Audibert et al. reported that IGFBP-1 screening did not predict preterm delivery and fFN screening provided the best predictive capacity. A policy of contingent use of testing for fFN after CL measurement or contingent use of CL measurement after fFN screening (depending on available resources) is a promising approach to limit use of resources [38]. Cooley et al. studied the relationship between levels of insulin-like growth factors 1 and 2 (IGF-1, IGF-2) and insulin-like growth factor binding protein 3 (IGFBP-3) in antenatal maternal serum and gestational age at delivery. They reported that there was no significant association between maternal IGF-1 or IGF-2 and preterm birth (PTB). Maternal mean IGFBP-3 levels are significantly reduced in cases complicated by delivery $<32$ completed weeks [39].

Cervicovaginal beta-hCG measurement in patients with preterm labor may be used as a predictive test. Bagga et al. studied with a group of 100 women with a singleton pregnancy with preterm labour between 26-36 weeks' gestation. Cervicovaginal secretions were collected for HCG assay and cervical length was measured by transvaginal sonography (TVS). These parameters were analysed to predict preterm birth. The preterm delivery rate was 55\%; $24 \%$ delivered within $48 \mathrm{~h}$ and $11 \%$ within 7 days of admission. The sensitivity, specificity, positive predictive value (PPV), and negative predictive values (NPV) of cervical length less than or equal to $2.5 \mathrm{~cm}$ to predict delivery within $48 \mathrm{~h}$ and 7 days of admission were $62.5 \%, 89.5 \%, 65.2 \%$, and $88.3 \%$ and $60.0 \%, 96.9 \%, 91.3 \%$, and $81.8 \%$, respectively; and those of qualitative HCG were $87.5 \%, 80.3 \%, 58.3 \%$, and $95.3 \%$ and $77.1 \%, 86.2 \%, 75 \%$, and $87.5 \%$, respectively. HCG value of $>$ or $=45 \mathrm{mIU} / \mathrm{mL}$ was the optimal cut-off, with a sensitivity, specificity, PPV, and NPV for predicting delivery within $48 \mathrm{~h}$ and 7 days to be $95.8 \%, 73.7 \%, 53.5 \%$, and $98.2 \%$ and $85.7 \%, 80 \%, 69.8 \%$, and $91.2 \%$, respectively. Combining either qualitative or quantitative HCG assay with cervical length significantly increased the sensitivity and NPV of cervical length alone for prediction of preterm delivery both within $48 \mathrm{~h}$ and 7 days. It was concluded that increased cervicovaginal HCG and reduced cervical length predicted an increased risk of preterm delivery in women with preterm labour. Qualitative cervicovaginal HCG assay may be used as a bedside test to predict preterm delivery within $48 \mathrm{~h}$ or within 7 days [40].

Adhikari et al. investigated prediction of the risk of preterm birth ( $<37$ weeks) or early preterm birth $(<34$ weeks) by cervicovaginal HCG and cervical length measured between 24 and 28 weeks of gestation in asymptomatic women at high risk for preterm birth. They reported that to predict delivery $<37$ weeks, cervical length $<2.95 \mathrm{~cm}$ had a sensitivity, specificity, positive predictive value (PPV), and negative predictive value (NPV) of 75\%, 80.1\%, 71.4\%, and 90.7\% respectively, and cervicovaginal HCG $>4.75 \mathrm{mIU} / \mathrm{mL}$ had a sensitivity, specificity, PPV, and NPV of 70\%, 61.81\%, $40 \%$, and $85 \%$, respectively. To predict delivery $<34$ weeks, cervical length $<2.65 \mathrm{~cm}$ had a sensitivity, specificity, PPV, and NPV of $50 \%, 85.50 \%, 23.08 \%$, and $95.16 \%$, respectively; and cervicovaginal HCG $>14 \mathrm{mIU} / \mathrm{mL}$ had a sensitivity, specificity, PPV, and NPV of $83.3 \%, 85.5 \%, 33.3 \%$, and $98.3 \%$, respectively. Cervical length was superior to predict delivery $<37$ weeks, whereas HCG was superior to predict delivery $<34$ weeks. Their combination was superior to predict preterm birth both $<37$ weeks or $<34$ weeks, than either parameter used alone [41].

Combined marker evaluation could be used as a sensitive parameter for identifying women at risk of spontaneous preterm delivery but it is not possible to obtain biomarkers in most of the clinics. Therefore, the evaluation of the cervix with utrasoundography is important.

\section{Cervical Assessment by Ultrasonography}

Cervix can be evaluated by transabdominal, translabial, and transvaginal ultrasound (TVU). Each technique has its costs and benefits; however, a review of the current literature will show that the transvaginal method of cervical assessment is the most reliable. TVU is objective, reproducible, and acceptable to patients. At the transabdominal approach, the cervix may not be visualised in up to $50 \%$ of cases unless the bladder is full, but bladder filling significantly increases the length of the cervix. The transperineal route is limited by 
both the inconsistency in correlation between transvaginal and transperineal measurements and the inadequate visualisation of the cervix in up to $25 \%$ of cases. Cervical changes such as dilatation of the internal cervical os with funneling (beaking) of the membranes can be easily appreciated by TVU, but not by digital examination [42-44]. The ultrasound images were analyzed to assess changes in the cervix that are associated with spontaneous prematurity and to evaluate ultrasonography as an indicator of the risk of preterm delivery [45].

Before the evaluation of the cervix with transvaginal ultrasonography, first of all, the patient should have an empty bladder and be placed in dorsal lithotomy position. A distended bladder can alter the shape of the cervix and compass the cervical canal in some cases preventing the detection of cervical incompetence $[44,46]$. The vaginal probe should be placed in the anterior fornix without pressure. If the probe is pressed too hard against the cervix, it can obscure cervical incompetence. Initial orientation is established by locating the sagittal view of the cervix. The cervical canal should appear as a hypoechoic groove. The junction between amniotic membrane and cervical canal is designated as the internal os. The external os is located at the lower end of the cervix. Cervical length (CL) is defined as the distance between the internal to external os along the endocervical canal (Figure 1). If the cervical canal is curved, the CL can be measured either as the sum of two straight lines that essentially follow the curve or by a straight line between internal and external os. A short CL is usually straight, and the presence of curved cervix generally signifies a CL greater than $25 \mathrm{~mm}$ and, therefore, is a reassuring finding $[47,48]$.

If the cervical canal is closed, CL is probably the only parameter that needs to be measured. If a normal appearing internal os cannot be visualized, the cervix should be assessed further to determine whether funneling (the internal os width is greater than $5 \mathrm{~mm}$ ) is present (Figure 2). If funneling is present, the shape can be recorded $[49,50]$. A continuous process of funneling has been described, going from a normal $\mathrm{T}$ shape to $\mathrm{Y}$, then $\mathrm{V}$, and finally a $\mathrm{U}$ shape. It appears that $\mathrm{U}$ shape is more likely to be associated with PTD, compared with a V-shaped funnel $[51,52]$.

CL during pregnancy can range from 25 to $70 \mathrm{~mm}$ and ultrasound width of the cervical canal ranges from 2 to $4 \mathrm{~mm}$ $[47,48,53,54]$. Percentile values for CL between 17 and 32 weeks of gestation are indicated in Table 1 (unpublished data). Before 14 weeks, it is difficult to distinguish the lower uterine segment from the endocervical canal. Therefore, the measurement of the true cervical length is very difficult before 14 weeks. There is agreement that the best time to examine patients with this method to estimate their preterm birth risk is between 18 and 24 gestational weeks. Several studies reported that the measurement of cervical length in the first trimester is not predictive of preterm delivery $[55,56]$. Finally, Greco et al. have recently reported that the endocervical length at 11 to 13 weeks is shorter in pregnancies resulting in spontaneous delivery before 34 weeks than in those delivering after 34 weeks [57].

Many parameters other than CL and presence or absence of a funnel have been studied including funnel width, funnel

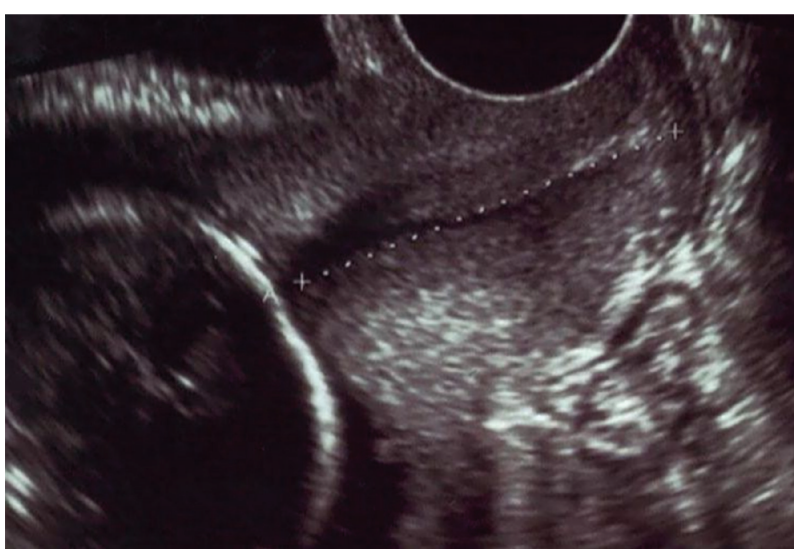

FIGURE 1: Transvaginal ultrasound image of the uterine cervix.

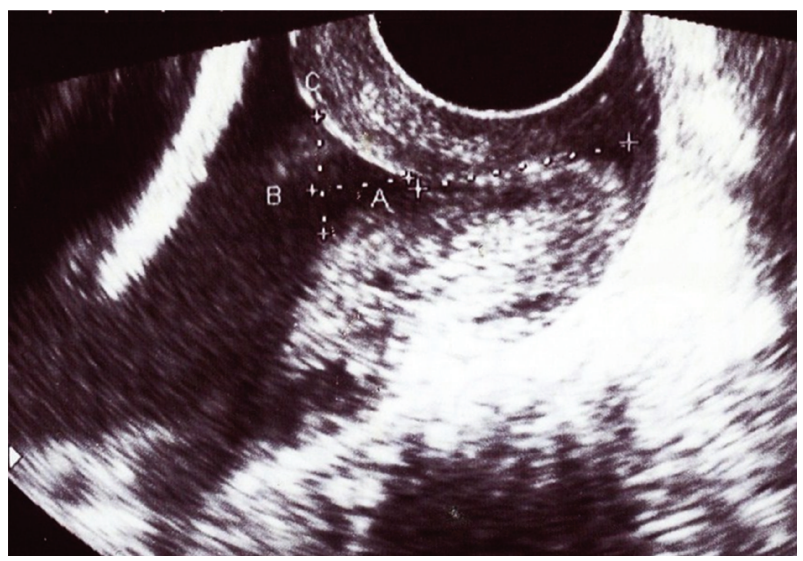

FIgURE 2: Transvaginal ultrasound image of the cervical funneling.

TABLE 1: Percentile values for CL between 17 and 32 weeks of gestation.

\begin{tabular}{lccccccc}
\hline \multirow{2}{*}{ Group (GW) } & \multicolumn{7}{c}{ Percentiles } \\
& 5 & 10 & 25 & 50 & 75 & 90 & 95 \\
\hline $17-20$ GW & 33,00 & 34,00 & 37,00 & 38,50 & 41,00 & 44,00 & 45,00 \\
21-24 GW & 29,00 & 30,00 & 34,50 & 37,00 & 39,00 & 41,00 & 43,00 \\
25-28 GW & 27,00 & 28,00 & 33,00 & 35,00 & 37,00 & 40,00 & 41,40 \\
29-32 GW & 26,50 & 28,00 & 31,00 & 33,00 & 36,50 & 39,00 & 40,00 \\
\hline
\end{tabular}

length, endocervical canal dilation, cervical index (funnel length +1 /functional length), anterior and posterior cervical width, cervical angle, cervical canal contour, and cervical gland area (CGA) [58-60].

\section{The Cervical Morphology and Biometry for the Prediction of Preterm Birth}

The length of the cervix may be useful in predicting the risk of premature delivery, with a shorter cervix predicting a higher risk. A short CL is a better predictor of early PTD than later PTD [47, 61-63]. In a prospective multicenter study, Iams et al. performed TVS of the cervix in low-risk women 
TABLE 2: Studies of CL measured by transvaginal ultrasonography to predict preterm birth in low-risk women.

\begin{tabular}{|c|c|c|c|c|c|c|c|c|}
\hline Authors & $n$ & GW at testing & Outcome (GW) & Cutoff value (mm) & Sen. $(\%)$ & Spec. (\%) & PPD (\%) & NPD $(\%)$ \\
\hline Tongsong et al. [6] & 730 & $28-30$ & $<37$ & $<35$ & 65.9 & 62.4 & 19.4 & 92.8 \\
\hline \multirow{4}{*}{ Iams et al. [47] } & \multirow{2}{*}{2915} & 24 & $<35$ & $\leq 30$ & 54.0 & 76.3 & 9.3 & 97.4 \\
\hline & & 24 & $<35$ & $\leq 25$ & 37.3 & 92.2 & 17.8 & 97.0 \\
\hline & \multirow{2}{*}{2531} & 28 & $<35$ & $\leq 30$ & 69.9 & 68.5 & 7.0 & 98.5 \\
\hline & & 28 & $<35$ & $\leq 25$ & 49.4 & 86.8 & 11.3 & 98.0 \\
\hline \multirow{2}{*}{ Fukami et al. [58] } & \multirow{2}{*}{3030} & \multirow{2}{*}{$16-19$} & $22-31$ & $\leq 30$ & 50.0 & 98.5 & 8.3 & 99.9 \\
\hline & & & $32-36$ & $\leq 30$ & 18.2 & 98.9 & 33.3 & 97.6 \\
\hline \multirow{2}{*}{ Pires et al. [59] } & \multirow{2}{*}{338} & \multirow{2}{*}{$21-24$} & $<37$ & $<20$ & 18.0 & 98.1 & 40.0 & 94.8 \\
\hline & & & $<35$ & $<20$ & 27.3 & 97.9 & 30.0 & 97.6 \\
\hline Barber et al. [7] & 2351 & $18-22$ & $<37$ & $<30$ & 39.0 & 92.0 & 31.0 & 94.0 \\
\hline
\end{tabular}

with a singleton pregnancy at 24 weeks $(n=2915)$ and 28 weeks $(n=2531)$ of gestation. At 24 weeks, a cervical length of $\leq 25 \mathrm{~mm}$ had a sensitivity of $37 \%$, a specificity of $92 \%$, a positive predictive value $18 \%$, and a negative predictive value $\% 97$ in predicting spontaneous preterm birth at $<35$ weeks' gestation. The RR of preterm birth before 35 weeks of gestation was about sixfold higher (95\% CI: 3.84-9.97) among women whose cervical length was less than $25 \mathrm{~mm}$ than that among women with a cervical length above $40 \mathrm{~mm}$ [47].

To et al. conducted a population-based prospective multicentre study in 39284 women with singleton pregnancies attending for routine hospital antenatal care in London, UK. The detection rate of spontaneous delivery before 32 weeks by measuring cervical length was $55 \%$, with $10 \%$ falsepositive rate [64]. Hibbard et al. measured the CL by TVS at 16-22 weeks in 760 singleton pregnancies in unselected women attending routine antenatal care. Relative risks (95\% CI) for spontaneous preterm delivery before 37 weeks were $3.8(2.6,5.6), 5.4(3.3,9.0)$, and $6.3(3.0,13.0)$ for the tenth $(30 \mathrm{~mm})$, fifth $(27 \mathrm{~mm})$, and two and a half $(22 \mathrm{~mm})$ percentiles, respectively; RRs for before 35 weeks were 4.5 $(2.9,6.9), 7.5(4.5,12.5)$, and $7.8(3.6,16.7)$. Sensitivity ranged from 13 to $44 \%$, specificity $90-99 \%$, positive predictive value $15-47 \%$, and negative predictive value $80-98 \%$ for prediction of preterm birth before 35 weeks [65].

A study of cervical length in low-risk women found an eightfold (95\% CI 3-19) increased risk of preterm birth when the cervix was less than $30 \mathrm{~mm}$ at 18 to 22 weeks of gestation, but the sensitivity and positive predictive values were low: 19 and 6 percent, respectively [61]. Although low sensitivity and low positive predictive value limit its usefulness, it has high negative predictive values and it can be used in screening of low-risk obstetric populations (Table 2).

A number of studies have assessed the predictive value of TVS CL in women with some of the most important of these risk factors including a prior PTD [50, 66, 67], a history of excisional cervical procedures (cone biopsy, LEEP) $[68,69]$, mullerian anomaly [70], and two or more voluntary termination [70] (Table 3). In a prospective study of 705 high-risk women, the risk of spontaneous PTB before 35 weeks decreased by approximately $6 \%$ for each additional millimeter of CL (OR: 0.94, 95\% CI: 0.92-0.95) and by approximately 5\% for each additional week of pregnancy during which the CL was measured (OR: 0.95, 95\% CI: 0.92$0.98)$. They conclude that gestational age at which transvaginal ultrasound cervical length is measured significantly affects the calculation of risk of spontaneous preterm birth. The spontaneous preterm birth risk increases as the length of the cervix declines and as the gestational age decreases [71].

Funneling comprising $40-50 \%$ of the total cervical length or a persistently shortened cervix $(<25-30 \mathrm{~mm})$ has, in several studies, been associated with an increased risk of preterm birth $[17,47,49,65]$. To et al. measured cervical length among 6334 women with singleton pregnancies at 22-24 weeks and looked for the presence of funneling to evaluate its possible additional risk. Funneling of the internal os was present in about $4 \%$ of pregnancies and the prevalence decreased with increasing cervical length from $98 \%$ when the length was $\leq 15 \mathrm{~mm}$ to about $25 \%$ for lengths of $16-30 \mathrm{~mm}$ and less than $1 \%$ at lengths of $>30 \mathrm{~mm}$. The rate of preterm delivery was $6.9 \%$ in those with funneling compared to $0.7 \%$ in those without funneling. However, logistic regression analysis demonstrated that funneling did not provide a significant additional contribution to cervical length in the prediction of spontaneous delivery before 33 weeks (OR, for short cervix $=24.9 P<0.0001 ;$ OR, for funneling $=1.8$, $P=0.40)$ [50].

As an independent finding, funneling does not add appreciably to the risk of early gestational age at delivery associated with a shortened cervical length. So, women with a long cervix and funneling are not at increased risk of preterm delivery $[50,51,72]$.

In the past few years publications have also highlighted the importance of another morphological ultrasonographic marker for PTD, named as the cervical gland area (CGA). The CGA is defined as the sonographically hipoechoic or hiperechoic zone surrounding the endocervical canal. If the CGA around the endocervical canal is not detected, it is defined as absent $[58,59]$.

Fukami et al. reported that the absence of CGA at second trimester ultrasonography appeared to be new and powerful predictor of PTD before 32 weeks gestation [58], similar to that reported by Pires et al. [59] (Table 4). Asakura et al. reported that short CL $(<20 \mathrm{~mm})$ with absent CGA represents an independent predictor for PTD. The absence of 
TABle 3: Studies of CL in high-risk women with spontaneous PTD.

\begin{tabular}{|c|c|c|c|c|c|c|c|c|c|}
\hline Authors & $n$ & GW at testing & Outcome (GW) & Cutoff value (mm) & Sen. $(\%)$ & Spec. (\%) & PPD (\%) & NPD (\%) & $\mathrm{RR}$ \\
\hline Berghella et al. [43] & 96 & $14-30$ & $<35$ & 25.0 & 59.0 & 85.0 & 45.0 & 91.0 & 4.8 \\
\hline Owen et al. [48] & 183 & $16-24$ & $<35$ & 25.0 & 69.0 & 80.0 & 55.0 & 88.0 & 3.4 \\
\hline Crane and Hutchens [66] & 193 & $24-30$ & $<35$ & 30.0 & 63.6 & 77.2 & 28.0 & 93.8 & - \\
\hline \multirow{2}{*}{ Adhikari et al. [41] } & \multirow{2}{*}{79} & \multirow{2}{*}{$24-28$} & $<37$ & 29.5 & 75.0 & 80.1 & 71.4 & 90.7 & - \\
\hline & & & $<34$ & 26.5 & 50.0 & 85.5 & 23.1 & 95.2 & - \\
\hline Berghella et al. [68] & 45 & $16-24$ & $<35$ & 25.0 & 60.0 & 69.0 & 35.0 & 86.0 & 2.5 \\
\hline Crane et al. [69] & 75 & $24-30$ & $<37$ & 30.0 & 70.0 & 90.8 & 53.8 & 95.2 & - \\
\hline Airoldi et al. [70] & 64 & $14-23^{+6}$ & $<35$ & 25.0 & 71.0 & 91.0 & 50.0 & 95.0 & 13.5 \\
\hline Visintine et al. [72] & 131 & $14-24$ & $<35$ & 25.0 & 53.0 & 75.0 & 48.0 & 78.0 & 2.2 \\
\hline
\end{tabular}

Table 4

\begin{tabular}{|c|c|c|c|c|c|c|c|c|}
\hline Authors & $n$ & GW at testing & Test & Outcome (GW) & Sen. $(\%)$ & Spec. $(\%)$ & PPD (\%) & $\operatorname{NPD}(\%)$ \\
\hline \multirow{4}{*}{ Fukami et al. [58] } & \multirow{4}{*}{3030} & \multirow{4}{*}{$16-19$} & Absence CGA & $22-31$ & 75.0 & 99.8 & 54.5 & 99.9 \\
\hline & & & $\mathrm{CL} \leq 30 \mathrm{~mm}+$ Absence CGA & $22-31$ & 50.0 & 99.8 & 40.0 & 99.9 \\
\hline & & & Absence CGA & $32-36$ & 2.3 & 99.7 & 18.2 & 97.2 \\
\hline & & & $\mathrm{CL} \leq 30 \mathrm{~mm}+$ Absence CGA & $32-36$ & 2.3 & 99.7 & 20.0 & 97.2 \\
\hline \multirow{2}{*}{ Pires et al. [59] } & \multirow{2}{*}{338} & \multirow{2}{*}{$21-24$} & Absence CGA & $<35$ & 54.5 & 99.1 & 66.7 & 98.5 \\
\hline & & & Absence CGA & $<37$ & 38.1 & 9.7 & 88.9 & 96.0 \\
\hline
\end{tabular}

the CGA as a new marker for the risk of PTD has to be confirmed by further investigations [73].

\section{Management Options for Short Cervix}

Many interventions have been proposed in an attempt to prevent PTD in women at high risk.

Bed rest and hydration are often recommended in an attempt to prevent PTD in women at high risk, but there is no consistent evidence that they are able to delay delivery [74].

Progesterone's role in the treatment and prevention of preterm birth is still uncertain. A Cochrane meta-analysis from 2005 showed that intramuscular progesterone is associated with a reduction in risk of preterm birth before 37 gestational weeks [75]. Fonseca et al. in a multicenter, randomized trial proposed using daily vaginal micronized progesterone (200 mg) to women with CL $15 \mathrm{~mm}$ or less, irrespective of other risk factors. They showed a significant reduction in preterm birth at $<34$ weeks with intravaginal progesterone in patients treated based on premature cervical shortening as the indication for therapy [76]. O'Brien et al. analyzed 547 randomized patients with a history of preterm birth. They found that the progesterone-treated patients had significantly less cervical shortening than the placebo group. A significant difference was also observed between groups for categorical outcomes including the frequency of cervical length progression to $\leq 25 \mathrm{~mm}$ and a $\geq 50 \%$ reduction in cervical length from baseline in this subpopulation [67]. Further research is necessary and several randomized trials are underway to clarify the efficacy and fetal safety of progesterone treat.

Cervical cerclage is an old, easily performed procedure for treatment of true cervical incompetence [77]. Dijkstra et al. studied 80 women whose primary physician determined that a prophylactic $(n=50)$ or urgent cerclage $(n=30)$ was indicated and had transvaginal ultrasonographic evaluation before and after cerclage. They found that the mean \pm standard deviation precerclage cervical length was $27.2 \pm$ $10.3 \mathrm{~mm}$ and after cerclage was $34.1 \pm 9.9 \mathrm{~mm}(n=80$, $P<0.001)$. The increase in cervical length after cerclage is not predictive of term delivery [78]. Until recently, cerclage was the only intervention studied to prevent PTB in asymptomatic women with short CL. Rust et al. randomized 113 women with $\mathrm{CL}<25 \mathrm{~mm}$ or $\geq 25 \%$ funneling measured between 16 and 24 weeks to either modified bed rest or cerclage. No significant differences between two groups regarding risk of PTB $<34$ weeks or perinatal death were noted. It is important that women were included based on an incidental finding of a short cervix without taking into account other risk factors in the maternal history. Therefore, the majority of women were considered low risk before the sonographic findings [79]. To et al. also sampled 47,123 asymptomatic women and identified a cervix of $15 \mathrm{~mm}$ or less in 470, of whom $253(54 \%)$ were randomized to either cervical cerclage $(n=127)$ or expectant management $(n=$ 126). No significant differences in the rate of $\mathrm{PTB}<33$ weeks or in perinatal or maternal morbidity or mortality were noted. Again, women in this study were incidentally found to have a short cervix. Subgroup analysis of the utility of cerclage in the high-risk population, based on maternal history, was not performed [80].

Cerclage is not indicated in low-risk patients. A casecontrolled study by Incerti et al. found that cerclage does not reduce $\mathrm{PTB}$ in low-risk women with short CL compared with rest alone. However, this is not the case in women with previous PTD. However, this is not the case in women with previous PTD [81]. A recent multicenter randomized trial included 302 women with at least one prior PTB $\leq 32$ weeks 
and TVU CL $<25 \mathrm{~mm}$ between 16 and $22^{6 / 7}$ weeks randomized to either cerclage or no cerclage. PTB $<35$ weeks was similar in both groups, but the benefit was most pronounced when CL was $<15 \mathrm{~mm}$, suggesting the presence of a more significant, and treatable, component of cervical insufficiency [82]. The systematic meta-analysis by Berghella et al. has shown that Cerclage, when performed in women with a singleton gestation, previous preterm birth, and cervical length $<25 \mathrm{~mm}$, seems to have a similar effect regardless of the degree of cervical shortening, including CL 16-24 mm, as well as CL $\leq 5.9 \mathrm{~mm}$ [83].

Weekly intramuscular 17-alpha-hydroxyprogesterone caproate $(17 \mathrm{P})$ was compared with McDonald cerclage in women with short CL $\leq 25 \mathrm{~mm}$ at between 16 and 24 weeks' gestation. The study was terminated, however, when the interim analysis showed no difference in PTD $<35$ weeks between treatment groups. However, cerclage may be more effective in preventing spontaneous PTD in women with CL $\leq 15 \mathrm{~mm}$ [84]. In another study, Berghella et al. showed that $17 \mathrm{P}$ had no additional benefit for prevention of PTD in women who had prior SPTD and got ultrasound-indicated cerclage for $\mathrm{CL}<25 \mathrm{~mm}$. In women who did not get cerclage, $17 \mathrm{P}$ reduced previable birth and perinatal mortality [85].

Evaluation of the cervical morphology and biometry with transvaginal ultrasonography at 16-24 weeks of gestation is a useful tool to predict the risk of preterm birth in low- and high-risk singleton pregnancies. For instance, a sonographic cervical length $>30 \mathrm{~mm}$ and present CGA have a $96-97 \%$ negative predictive value for preterm delivery at $<37$ weeks. Transvaginal evaluation of cervix during routine fetal morphological examination helps identify asymptomatic low- and high-risk women for prediction of preterm delivery. Available evidence supports the use of progesterone to women with cervical length $\leq 25 \mathrm{~mm}$, irrespective of other risk factors. In women with prior spontaneous PTD with asymptomatic cervical shortening ( $\mathrm{CL} \leq 25 \mathrm{~mm}$ ) there should be prophylactic cerclage procedure and weekly to every two weeks follow-up.

\section{References}

[1] P. J. Meis, R. L. Goldenberg, B. M. Mercer et al., "The preterm prediction study: risk factors for indicated preterm births," American Journal of Obstetrics and Gynecology, vol. 178, no. 3, pp. 562-567, 1998.

[2] R. L. Goldenberg, J. F. Culhane, J. D. Iams, and R. Romero, "Epidemiology and causes of preterm birth," The Lancet, vol. 371, no. 9606, pp. 75-84, 2008.

[3] E. Celik, M. To, K. Gajewska, G. C. S. Smith, and K. H. Nicolaides, "Cervical length and obstetric history predict spontaneous preterm birth: development and validation of a model to provide individualized risk assessment," Ultrasound in Obstetrics and Gynecology, vol. 31, no. 5, pp. 549-554, 2008.

[4] J. A. Martin, B. E. Hamilton, P. D. Sutton et al., "Births: final data for 2007," National Vital Statistics Reports, vol. 58, pp. 1$85,2010$.

[5] J. A. Martin, M. J. Osterman, and P. D. Sutton, "Are preterm births on the decline in the United States? Recent data from the National Vital Statistics System," NCHS Data Brief, vol. 39, pp. $1-8,2010$.
[6] T. Tongsong, P. Kamprapanth, J. Srisomboon, C. Wanapirak, W. Piyamongkol, and S. Sirichotiyakul, "Single transvaginal sonographic measurement of cervical length early in the third trimester as a predictor of preterm delivery," Obstetrics and Gynecology, vol. 86, no. 2, pp. 184-187, 1995.

[7] M. A. Barber, I. Eguiluz, W. Plasencia, M. Medina, L. Valle, and J. A. Garcia, "Preterm delivery and ultrasound measurement of cervical length in Gran Canaria, Spain," International Journal of Gynecology and Obstetrics, vol. 108, no. 1, pp. 5860, 2010.

[8] S. L. Buchanan, C. A. Crowther, K. M. Levett, P. Middleton, and J. Morris, "Planned early birth versus expectant management for women with preterm prelabour rupture of membranes prior to 37 weeks' gestation for improving pregnancy outcome," Cochrane Database of Systematic Reviews, vol. 3, Article ID CD004735, 2010.

[9] B. J. Stoll, N. I. Hansen, E. F. Bell et al., "Neonatal outcomes of extremely preterm infants from the NICHD Neonatal Research Network," Pediatrics, vol. 126, no. 3, pp. 443-456, 2010.

[10] J. D. Iams and V. Berghella, "Care for women with prior preterm birth," American Journal of Obstetrics and Gynecology, vol. 203, no. 2, pp. 89-100, 2010.

[11] F. Raga, C. Bauset, J. Remohi, F. Bonilla-Musoles, C. Simón, and A. Pellicer, "Reproductive impact of congenital Mullerian anomalies," Human Reproduction, vol. 12, no. 10, pp. 22772281, 1997.

[12] B. W. Rackow and A. Arici, "Reproductive performance of women with müllerian anomalies," Current Opinion in Obstetrics and Gynecology, vol. 19, no. 3, pp. 229-237, 2007.

[13] G. G. G. Donders, I. Riphagen, and T. Van Den Bosch, "Abnormal vaginal flora, cervical length and preterm birth," Ultrasound in Obstetrics and Gynecology, vol. 16, no. 5, pp. 496-497, 2000.

[14] G. G. Donders, K. Van Calsteren, G. Bellen et al., "Predictive value for preterm birth of abnormal vaginal flora, bacterial vaginosis and aerobic vaginitis during the first trimester of pregnancy," British Journal of Obstetrics and Gynaecology, vol. 116, no. 10, pp. 1315-1324, 2009.

[15] R. F. Lamont and D. Taylor-Robinson, "The role of bacterial vaginosis, aerobic vaginitis, abnormal vaginal flora and the risk of preterm birth," British Journal of Obstetrics and Gynaecology, vol. 117, no. 1, pp. 119-120, 2010.

[16] M. R. Peltier, "Immunology of term and preterm labor," Reproductive Biology and Endocrinology, vol. 1, article 122, 2003.

[17] J. G. Mauldin and R. B. Newman, "Preterm birth risk assessment," Seminars in Perinatology, vol. 25, no. 4, pp. 215-222, 2001.

[18] J. P. Reichmann, "Home uterine activity monitoring: the role of medical evidence," Obstetrics and Gynecology, vol. 112, no. 2, pp. 325-327, 2008.

[19] C. J. Lockwood, A. E. Senyei, M. R. Dische et al., "Fetal fibronectin in cervical and vaginal secretions as a predictor of preterm delivery," New England Journal of Medicine, vol. 325, no. 10, pp. 669-674, 1991.

[20] R. L. Goldenberg, B. M. Mercer, P. J. Meis, R. L. Copper, A. Das, and D. McNellis, "The preterm prediction study: fetal fibronectin testing and spontaneous preterm birth," Obstetrics and Gynecology, vol. 87, no. 5 I, pp. 643-648, 1996.

[21] A. Herbst and C. Nilsson, "Diagnosis of early preterm labour," British Journal of Obstetrics and Gynaecology, vol. 113, no. 3, pp. 60-67, 2006.

[22] H. Honest, L. M. Bachmann, J. K. Gupta, J. Kleijnen, and K. S. Khan, "Accuracy of cervicovaginal fetal fibronectin test 
in predicting risk of spontaneous preterm birth: systematic review," British Medical Journal, vol. 325, no. 7359, pp. 301304, 2002.

[23] V. Berghella, E. Hayes, J. Visintine, and J. K. Baxter, "Fetal fibronectin testing for reducing the risk of preterm birth," Cochrane Database of Systematic Reviews, vol. 8, Article ID CD006843, 2008.

[24] M. Chandiramani, G. C. Di Renzo, E. Gottschalk et al., "Fetal fibronectin as a predictor of spontaneous preterm birth: a European perspective," Journal of Maternal-Fetal and Neonatal Medicine, vol. 24, no. 2, pp. 330-336, 2011.

[25] C. Deplagne, S. Maurice-Tison, F. Coatleven, F. Vandenbossche, and J. Horovitz, "Sequential use of cervical length measurement before fetal fibronectin detection to predict spontaneous preterm delivery in women with preterm labor," Journal de Gynecologie Obstetrique et Biologie de la Reproduction, vol. 39, no. 7, pp. 575-583, 2010.

[26] R. P. Heine, J. A. McGregor, T. M. Goodwin et al., "Serial salivary estriol to detect an increased risk of preterm birth," Obstetrics and Gynecology, vol. 96, no. 4, pp. 490-497, 2000.

[27] P. S. Ramsey and W. W. Andrews, "Biochemical predictors of preterm labor: fetal fibronectin and salivary estriol," Clinics in Perinatology, vol. 30, no. 4, pp. 701-733, 2003.

[28] K. Hurt and R. Pruner, "Prematurity and methods of its screening," Ceska Gynekologie, vol. 71, no. 1, pp. 3-6, 2006.

[29] W. Yuan, L. Chen, and A. López Bernal, "Is elevated maternal serum alpha-fetoprotein in the second trimester of pregnancy associated with increased preterm birth risk?. A systematic review and meta-analysis," European Journal of Obstetrics Gynecology and Reproductive Biology, vol. 145, no. 1, pp. 5764, 2009.

[30] K. W. Marvin, J. A. Keelan, M. A.G. Coleman, L. M.E. McCowan, R. L. Zhou, and M. D. Mitchell, "Intercellular adhesion molecue-1 (ICAM-1) in cervicovaginal fluid of women presenting with preterm labor: predictive value for preterm delivery," American Journal of Reproductive Immunology, vol. 43, no. 5, pp. 264-271, 2000.

[31] H. S. Kwon, I. S. Sohn, J. Y. Lee, S. J. Lee, S. N. Kim, and B. J. Kim, "Intercellular adhesion molecule-1 K469E polymorphism in Korean patients with spontaneous preterm delivery," International Journal of Gynecology and Obstetrics, vol. 104, no. 1, pp. 37-39, 2009.

[32] F. Akercan, M. Kazandi, F. Sendag et al., "Value of cervical phosphorylated insulinlike growth factor binding protein-1 in the prediction of preterm labor," Journal of Reproductive Medicine for the Obstetrician and Gynecologist, vol. 49, no. 5, pp. 368-372, 2004.

[33] L. Rahkonen, L. Unkila-Kallio, E. M. Rutanen, and J. Paavonen, "Factors affecting decidual IGFBP-1 levels in the vagina and cervix in the first and mid-second trimester of pregnancy," British Journal of Obstetrics and Gynaecology, vol. 116, no. 1, pp. 45-54, 2009.

[34] L. Rahkonen, E. M. Rutanen, M. Nuutila, S. Sainio, T. Saisto, and J. Paavonen, "Elevated levels of decidual insulin-like growth factor binding protein-1 in cervical fluid in early and mid-pregnancy are associated with an increased risk of spontaneous preterm delivery," British Journal of Obstetrics and Gynaecology, vol. 117, no. 6, pp. 701-710, 2010.

[35] L. Rahkonen, L. Unkila-Kallio, M. Nuutila et al., "Cervical length measurement and cervical phosphorylated insulinlike growth factor binding protein-1 testing in prediction of preterm birth in patients reporting uterine contractions," Acta Obstetricia et Gynecologica Scandinavica, vol. 88, no. 8, pp. 901-908, 2009.
[36] D. Paternoster, F. Riboni, A. Vitulo et al., "Phosphorylated insulin-like growth factor binding protein-1 in cervical secretions and sonographic cervical length in the prediction of spontaneous preterm delivery," Ultrasound in Obstetrics and Gynecology, vol. 34, no. 4, pp. 437-440, 2009.

[37] R. E. Bittar, E. B. Da Fonseca, M. H. B. De Carvalho, S. Martinelli, and M. Zugaib, "Predicting preterm delivery in asymptomatic patients with prior preterm delivery by measurement of cervical length and phosphorylated insulin-like growth factor-binding protein-1," Ultrasound in Obstetrics and Gynecology, vol. 29, no. 5, pp. 562-567, 2007.

[38] F. Audibert, S. Fortin, E. Delvin et al., "Contingent use of fetal fibronectin testing and cervical length measurement in women with preterm labour," Journal of Obstetrics and Gynaecology Canada, vol. 32, no. 4, pp. 307-312, 2010.

[39] S. M. Cooley, J. C. Donnelly, C. Collins, M. P. Geary, C. H. Rodeck, and P. C. Hindmarsh, "The relationship between maternal insulin-like growth factors 1 and 2 (IGF-1, IGF-2) and IGFBP-3 to gestational age and preterm delivery," Journal of Perinatal Medicine, vol. 38, no. 3, pp. 255-259, 2010.

[40] R. Bagga, M. Takhtani, V. Suri, K. Adhikari, S. Arora, and S. Bhardwaj, "Cervical length and cervicovaginal HCG for prediction of pre-term birth in women with signs and symptoms of pre-term labour," Journal of Obstetrics and Gynaecology, vol. 30, no. 5, pp. 451-455, 2010.

[41] K. Adhikari, R. Bagga, V. Suri, S. Arora, and S. Masih, "Cervicovaginal HCG and cervical length for prediction of preterm delivery in asymptomatic women at high risk for preterm delivery," Archives of Gynecology and Obstetrics, vol. 280, no. 4, pp. 565-572, 2009.

[42] O. Okitsu, T. Mimura, T. Nakayama, and T. Aono, "Early prediction of preterm delivery by transvaginal ultrasonography," Ultrasound in Obstetrics \& Gynecology, vol. 2, pp. 402-409, 1992.

[43] V. Berghella, J. E. Tolosa, K. Kuhlman, S. Weiner, R. J. Bolognese, and R. J. Wapner, "Cervical ultrasonography compared with manual examination as a predictor of preterm delivery," American Journal of Obstetrics and Gynecology, vol. 177, no. 4, pp. 723-730, 1997.

[44] M. S. To, C. Skentou, C. Chan, A. Zagaliki, and K. H. Nicolaides, "Cervical assessment at the routine 23-week scan: standardizing techniques," Ultrasound in Obstetrics and Gynecology, vol. 17, no. 3, pp. 217-219, 2001.

[45] H. Leitich, M. Brunbauer, A. Kaider, C. Egarter, and P. Husslein, "Cervical length and dilatation of the internal cervical os detected by vaginal ultrasonography as markers for preterm delivery: a systematic review," American Journal of Obstetrics and Gynecology, vol. 181, no. 6, pp. 1465-1472, 1999.

[46] N. P. Yost, S. L. Bloom, D. M. Twickler, and K. J. Leveno, "Pitfalls in ultrasonic cervical length measurement for predicting preterm birth," Obstetrics and Gynecology, vol. 93, no. 4, pp. 510-516, 1999.

[47] J. D. Iams, R. L. Goldenberg, P. J. Meis et al., "The length of the cervix and the risk of spontaneous premature delivery," New England Journal of Medicine, vol. 334, no. 9, pp. 567-572, 1996.

[48] J. Owen, N. Yost, V. Berghella et al., "Mid-trimester endovaginal sonography in women at high risk for spontaneous preterm birth," Journal of the American Medical Association, vol. 286, no. 11, pp. 1340-1348, 2001.

[49] V. Berghella, K. Kuhlman, S. Weiner, L. Texeira, and R. J. Wapner, "Cervical funneling: sonographic criteria predictive of preterm delivery," Ultrasound in Obstetrics and Gynecology, vol. 10, no. 3, pp. 161-166, 1997. 
[50] M. S. To, C. Skentou, A. W. Liao, A. Cacho, and K. H. Nicolaides, "Cervical length and funneling at 23 weeks of gestation in the prediction of spontaneous early preterm delivery," Ultrasound in Obstetrics and Gynecology, vol. 18, no. 3, pp. 200-203, 2001.

[51] V. Berghella, J. Owen, C. MacPherson et al., "Natural history of cervical funneling in women at high risk for spontaneous preterm birth," Obstetrics and Gynecology, vol. 109, no. 4, pp. 863-869, 2007.

[52] M. Zilianti, A. Azuaga, F. Calderon, and C. Redondo, "Transperineal sonography in second trimester to term pregnancy and early labor," Journal of Ultrasound in Medicine, vol. 10, no. 9, pp. 481-485, 1991.

[53] O. Kushnir, D. A. Vigil, L. Izquierdo, M. Schiff, and L. B. Curet, "Vaginal ultrasonographic assessment of cervical length changes during normal pregnancy," American Journal of Obstetrics and Gynecology, vol. 162, no. 4, pp. 991-993, 1990.

[54] D. Gramellini, S. Fieni, E. Molina, R. Berretta, and E. Vadora, "Transvaginal sonographic cervical length changes during normal pregnancy," Journal of Ultrasound in Medicine, vol. 21, no. 3, pp. 227-232, 2002.

[55] G. Conoscenti, Y. J. Meir, G. D’Ottavio et al., "Does cervical length at 13-15 weeks' gestation predict preterm delivery in an unselected population?" Ultrasound in Obstetrics and Gynecology, vol. 21, no. 2, pp. 128-134, 2003.

[56] I. Ozdemir, F. Demirci, O. Yucel, and U. Erkorkmaz, "Ultrasonographic cervical length measurement at 10-14 and 2024 weeks gestation and the risk of preterm delivery," European Journal of Obstetrics Gynecology and Reproductive Biology, vol. 130, no. 2, pp. 176-179, 2007.

[57] E. Greco, A. Lange, F. Ushakov, J. R. Calvo, and K. H. Nicolaides, "Prediction of spontaneous preterm delivery from endocervical length at 11 to 13 weeks," Prenatal Diagnosis, vol. 31, no. 1, pp. 84-89, 2011.

[58] T. Fukami, K. Ishihara, T. Sekiya, and T. Araki, "Is transvaginal ultrasonography at mid-trimester useful for predicting early spontaneous preterm birth?" Journal of Nippon Medical School, vol. 70, no. 2, pp. 135-140, 2003.

[59] C. R. Pires, A. F. Moron, R. Mattar, A. L. D. Diniz, S. G. A. Andrade, and L. C. S. Bussamra, "Cervical gland area as an ultrasonographic marker for preterm delivery," International Journal of Gynecology and Obstetrics, vol. 93, no. 3, pp. 214219, 2006.

[60] N. P. Yost, J. Owen, V. Berghella et al., "Second-trimester cervical sonography: features other than cervical length to predict spontaneous preterm birth," Obstetrics and Gynecology, vol. 103, no. 3, pp. 457-462, 2004.

[61] P. Taipale and V. Hiilesmaa, "Sonographic measurement of uterine cervix at 18-22 weeks' gestation and the risk of preterm delivery," Obstetrics and Gynecology, vol. 92, no. 6, pp. 902907, 1998.

[62] V. C. F. Heath, T. R. Southall, A. P. Souka, A. Elisseou, and K. H. Nicolaides, "Cervical length at 23 weeks of gestation: prediction of spontaneous preterm delivery," Ultrasound in Obstetrics and Gynecology, vol. 12, no. 5, pp. 312-317, 1998.

[63] V. Berghella, A. Roman, C. Daskalakis, A. Ness, and J. K. Baxter, "Gestational age at cervical length measurement and incidence of preterm birth," Obstetrics and Gynecology, vol. 110, no. 2 I, pp. 311-317, 2007.

[64] M. S. To, C. A. Skentou, P. Royston, C. K. H. Yu, and K. H. Nicolaides, "Prediction of patient-specific risk of early preterm delivery using maternal history and sonographic measurement of cervical length: a population-based prospective study," Ultrasound in Obstetrics and Gynecology, vol. 27, no. 4, pp. 362-367, 2006.

[65] J. U. Hibbard, M. Tart, and A. H. Moawad, "Cervical length at 16-22 weeks' gestation and risk for preterm delivery," Obstetrics and Gynecology, vol. 96, no. 6, pp. 972-978, 2000.

[66] J. M. G. Crane and D. Hutchens, "Use of transvaginal ultrasonography to predict preterm birth in women with a history of preterm birth," Ultrasound in Obstetrics and Gynecology, vol. 32, no. 5, pp. 640-645, 2008.

[67] J. M. O’Brien, E. A. DeFranco, C. D. Adair et al., "Effect of progesterone on cervical shortening in women at risk for preterm birth: secondary analysis from a multinational, randomized, double-blind, placebo-controlled trial," Ultrasound in Obstetrics and Gynecology, vol. 34, no. 6, pp. 653-659, 2009.

[68] V. Berghella, L. Pereira, A. Gariepy, and G. Simonazzi, "Prior cone biopsy: prediction of preterm birth by cervical ultrasound," American Journal of Obstetrics and Gynecology, vol. 191, no. 4, pp. 1393-1397, 2004.

[69] J. M. G. Crane, T. Delaney, and D. Hutchens, “Transvaginal ultrasonography in the prediction of preterm birth after treatment for cervical intraepithelial neoplasia," Obstetrics and Gynecology, vol. 107, no. 1, pp. 37-44, 2006.

[70] J. Airoldi, V. Berghella, H. Sehdev, and J. Ludmir, "Transvaginal ultrasonography of the cervix to predict preterm birth in women with uterine anomalies," Obstetrics and Gynecology, vol. 106, no. 3, pp. 553-556, 2005.

[71] V. Berghella and A. Roman, "Does funneling increase the incidence of preterm birth in women with normal cervical length?" American Journal of Obstetrics \& Gynecology, vol. 193, p. 147, 2005.

[72] J. Visintine, V. Berghella, D. Henning, and J. Baxter, "Cervical length for prediction of preterm birth in women with multiple prior induced abortions," Ultrasound in Obstetrics and Gynecology, vol. 31, no. 2, pp. 198-200, 2008.

[73] H. Asakura, T. Fukami, R. Kurashina, N. Tateyama, D. Doi, and T. Takeshita, "Significance of cervical gland area in predicting preterm birth for patients with threatened preterm delivery: comparison with cervical length and fetal fibronectin," Gynecologic and Obstetric Investigation, vol. 68, no. 1, pp. $1-8,2009$.

[74] R. L. Goldenberg, S. P. Cliver, J. Bronstein, G. R. Cutter, W. W. Andrews, and S. T. Mennemeyer, "Bed rest in pregnancy," Obstetrics and Gynecology, vol. 84, no. 1, pp. 131-136, 1994.

[75] J. M. Dodd, V. Flenady, R. Cincotta, and C. A. Crowther, "Prenatal administration of progesterone for preventing preterm birth," Cochrane Database of Systematic Reviews, no. 1, Article ID CD004947, 2006.

[76] E. B. Fonseca, E. Celik, M. Parra, M. Singh, and K. H. Nicolaides, "Progesterone and the risk of preterm birth among women with a short cervix," New England Journal of Medicine, vol. 357, no. 5, pp. 462-469, 2007.

[77] J. U. Hibbard, J. Snow, and A. H. Moawad, "Short cervical length by ultrasound and cerclage," Journal of Perinatology, vol. 20, no. 3, pp. 161-165, 2000.

[78] K. Dijkstra, E. F. Funai, L. O’Neill, A. Rebarber, M. J. Paidas, and B. K. Young, "Change in cervical length after cerclage as a predictor of preterm delivery," Mechanisms of Development, vol. 96, no. 2, pp. 346-350, 2000.

[79] O. A. Rust, R. O. Atlas, J. Reed, J. Van Gaalen, and J. Balducci, "Revisiting the short cervix detected by transvaginal ultrasound in the second trimester: why cerclage therapy may not help," American Journal of Obstetrics and Gynecology, vol. 185, no. 5, pp. 1098-1105, 2001. 
[80] M. S. To, Z. Alfirevic, V. C. F. Heath et al., "Cervical cerclage for prevention of preterm delivery in women with short cervix: randomised controlled trial," Lancet, vol. 363, no. 9424, pp. 1849-1853, 2004.

[81] M. Incerti, A. Ghidini, A. Locatelli, S. H. Poggi, and J. C. Pezzullo, "Cervical length $\leq 25 \mathrm{~mm}$ in low-risk women: a case control study of cerclage with rest vs rest alone," American Journal of Obstetrics and Gynecology, vol. 197, no. 3, pp. 315.e1-315.e4, 2007.

[82] J. Owen, G. Hankins, J. D. Iams et al., "Multicenter randomized trial of cerclage for preterm birth prevention in highrisk women with shortened midtrimester cervical length," American Journal of Obstetrics and Gynecology, vol. 201, no. 4, pp. 375.e1-375.e8, 2009.

[83] V. Berghella, S. M. Keeler, M. S. To, S. M. Althuisius, and O. A. Rust, "Effectiveness of cerclage according to severity of cervical length shortening: a meta-analysis," Ultrasound in Obstetrics and Gynecology, vol. 35, no. 4, pp. 468-473, 2010.

[84] S. M. Keeler, D. Kiefer, M. Rochon, J. N. Quinones, A. P. Novetsky, and O. Rust, "A randomized trial of cerclage vs. $17 \alpha$ hydroxyprogesterone caproate for treatment of short cervix," Journal of Perinatal Medicine, vol. 37, no. 5, pp. 473-479, 2009.

[85] V. Berghella, D. Figueroa, J. M. Szychowski et al., "17-alphahydroxyprogesterone caproate for the prevention of preterm birth in women with prior preterm birth and a short cervical length," American Journal of Obstetrics and Gynecology, vol. 202, no. 4, pp. 351.e1-351.e6, 2010. 


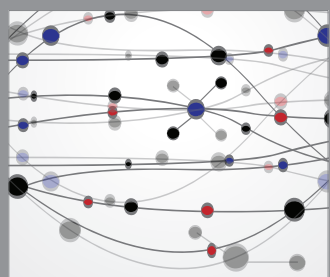

The Scientific World Journal
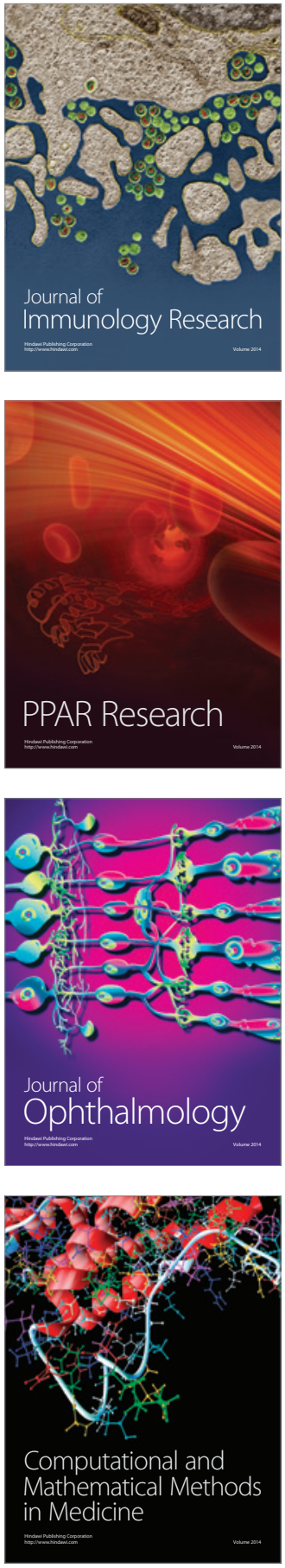

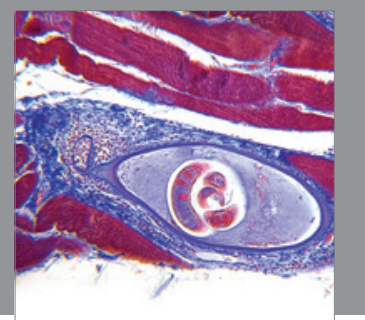

Gastroenterology

Research and Practice
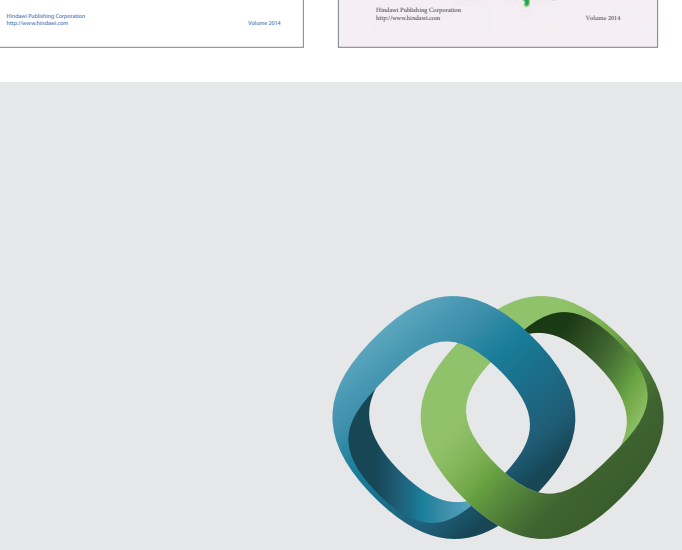

\section{Hindawi}

Submit your manuscripts at

http://www.hindawi.com
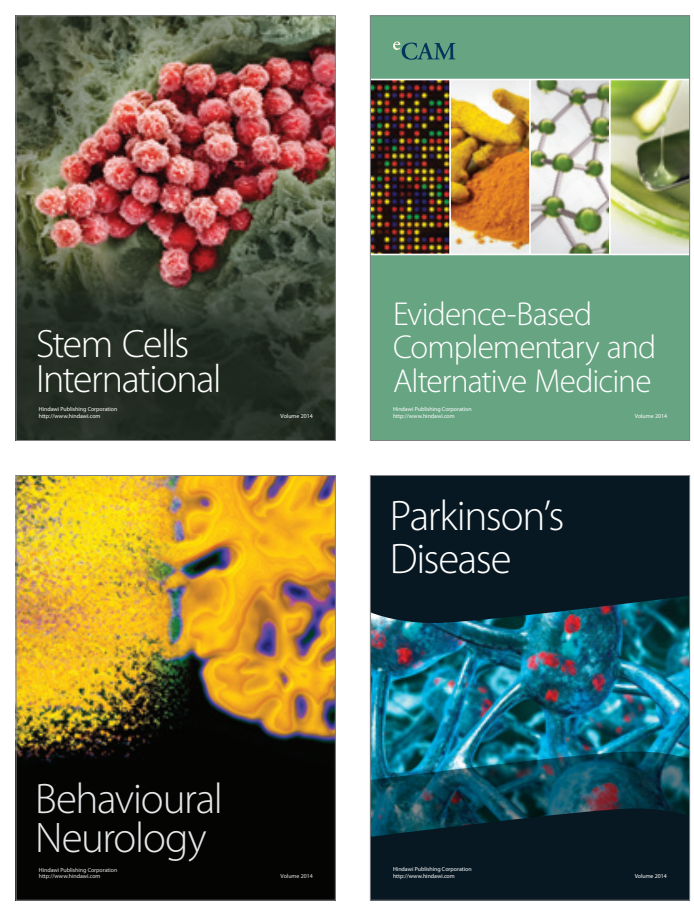

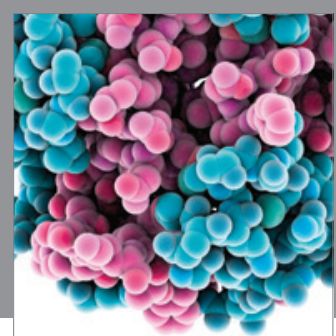

Journal of
Diabetes Research

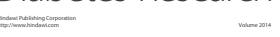

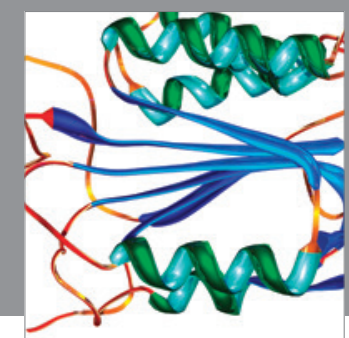

Disease Markers
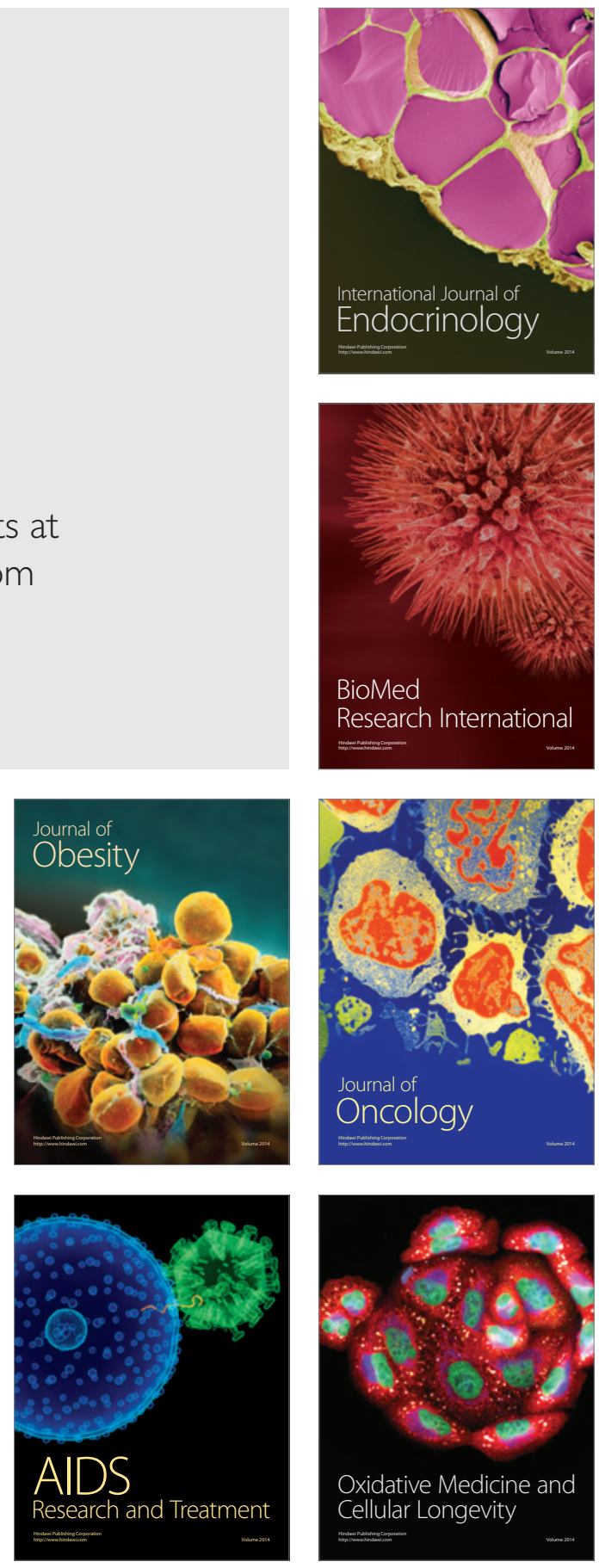